\title{
Cytological and cytochemical changes of liver cells of an osseous fish caused by the alteration of water temperature \\ II On polysaccharide and protein
}

\author{
Seiji Minamitani \\ Department of Anatomy, School of Medicine, Keio-Gijuku University, Tokyo
}

A considerable number of cytological studies has been reported on the effect of raising and lowering of atmospheric temperature upon animal hepatic cells. Particularly the fate of glycogen was observed by Böhm et Hoffmann (1878), Takeuchi (1910) or Owaki et Watanabe (1923). The author reports in this paper on the changes of polysaccharide and protein of liver cells of an osseous fish, caused by relatively rapid changes of water temperature.

\section{Material and Method}

As the animal for experiment an osseous fish, Oryzias latipes, was chosen. The same method as described in the previous paper (Minamitani, 1953) was used. After the fixation with $70 \%$ alcohol, paraffin sections were cut, and Hotchkiss's periodic acid method (1946) for polysaccharide and Yasuma et Ichikawa's ninhydrin. Schiff's reagent method (1951) for protein were applied on these sections. After the former method nuclei were counterstained with Heidenhain's iron hematoxylin.

\section{Observations}

Polysaccharide :

The picture in the control cases (fig. 1) is similar to that obtained by Tsukuda (1952). In the cases of low temperature group (fig. 2), diffusely stained parts are decreased, and intensely stained threads are clearly demonstrated. Each parts of cytoplasm show a coloration of similar intensity. Nucleus gives no positive reaction for polysaccharide. 
In the high temperature cases (fig. 3), a general decrease of polysaccharide is observed, and a considerable number of vacuoles, which contain no polysaccharide, is seen. Around these vacuoles irregular-shaped granules are stained relatively intensely. It is impossible to determine whether these granules are or not the same ones, which show strongly positive alkaline phosphatase reaction in the similar experiment carried out by the author previously (Minamitani, 1953). Such a decrease of polysaccharide agrees with the results by Nozaka (1927) observed in mouse. After digesting the sections with $1 \%$ diastase solution at $37^{\circ} \mathrm{C}$. for 24 .hours, the red color is hardly visible, and this fact suggests that the intense red coloration means the presence of glycogen.

Protein :

In the control group (fig. 4), nucleolus and nuclear membrane stand out more intensely stained than cytoplasm does. In nucleus there exists an obscure red stained network, more weakly stained than cytoplasm. Cytoplasm is relatively intensely and diffusely stained, and within itself containes threads, which are stained more intensely than surrounding cytoplasm. These threads are considered probably to be mitochondria from their shape and localization. Different parts of cytoplasm show the same intensity of colour.

In the low temperature group (fig. 5), in comparison with the control cases, the stainability of nucleolus and nuclear membrane is almost similar to that of the latter, on the other hand the network in nucleus is more clearly seen than that of the latter. Cytoplasm decreases its colour intensity, and the threads in cytoplasm can be more clearly demonstrated. Different parts of cytoplasm of a single hepatic cell show sometimes different intensity of stainability, but the localization of weaker reaction is irregularly distributed.

In the high temperature group (fig. 6), nucleolus and nuclear membrane are stained more strongly than the control, and the network in nucleus is markedly clearly demonstrated. Cytoplasm contains unstained vacuoles. The stainability of whole cytoplasm decreases, threads, which are stained more intensely than surrounding cytoplasm in the low temperature cases, are hardly distinguished. The granules, which are demonstrated around vacuoles in the polysaccharide test, can not be found in this protein reaction. 


\section{Summary}

1. Polysaccharide and protein in liver cells of Oryzias latipes, which were kept in the water of room temperature, of $0^{\circ} \mathrm{C}$. and of $31-32^{\circ} \mathrm{C}$., were examined.

2. Polysaccharide decreases to some extent in the low temperature experiment, and diminishes markedly in the high temperature experiment.

3. In the low temperature experiment, a change of protein in nucleus is scarcely realized, whereas the amount of protein in cytoplasm decreases.

In the high temperature experiment, the amount of protein increases in nucleus and decreases in cytoplasm.

\section{References}

Böhm, R. and Hoffmann, A. 1878 Über den Verbrauch der Kohlenhydrate im thierischen Organismus unter dem Einfluss von Wärmeentziehung. Arch. exp. Path. u. Pharm. Bd. 8 S. 375.

Hotchkiss, R.D. 1946 from D. Glick 1949 Techniques of Histo-and Cytochemistry. Minamitani, S. 1953 Cytological and cytochemical changes of liver cells of an osseous fish caused by the alteration of water temperature. I On alkaline and acid phosphatase Fol. Anat. Jap. Bd. 25 S. 19

Nozaka, T. 1927 Über den Einfluss der Aussentemperatur auf Leberglykogen und Fett, insbesondere über die Beziehung der Aussentemperatur zu den Veränderungen der Schilddrü se und Nebenniere. Fol. Endocrin. Jap. Bd. 3 S. 1558 (Japanese)

Owaki, S. and Watanabe, A. 1923 Experimental studies on influences of low temperature upon living bodies. I Histopathologic and histochemical studies. HokkaidoIgaku-Zasshi vol. 14 p. 491 (Japanese)

Takeuchi, K. 1910 Experimental and clinical studies on pathology of burns and chilblain. Nisshin-Igaku vol. 12 p. 11 (Japanese)

Tsukuda, T. 1952 On the mitochondria, ribonucleic acid, acid phosphatase and polysaccharide of liver cells of a fish (Oryzias latipes) during starvation. II On acid phosphatase. Fol. Anat. Jap. Bd. 24 S. 103.

Yasuma, A. and Ichikawa T. 1951 A new cytochemical staining of protein. Medicine and Biology vol. 19 p. 197 (Japanese)

\section{Explanation of figures}

Fig. 1-3 polysaccharide, stained with PAS method and Heidenhain's iron hematoxylin.

Fig. 4-6 protein, stained with ninhydrin-Schiff's reagent method.

Fig. 1 and 4 control

Fig. 2 and 5 low temperature experiment group.

Fig. 3 and 6 high temperature experiment group. 


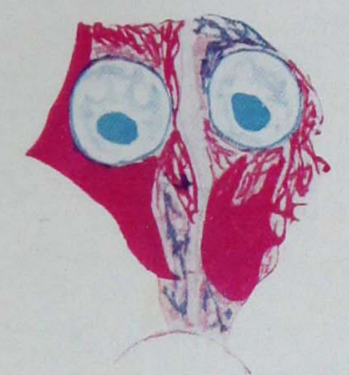

Fig. 1

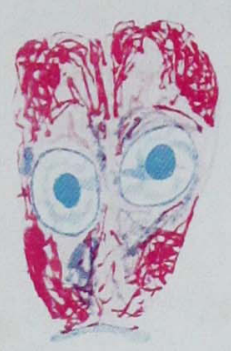

Fig. 2

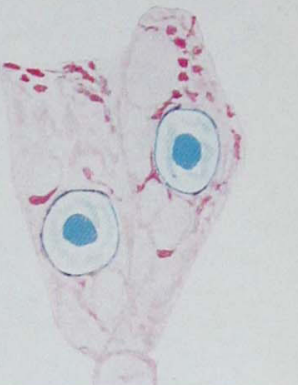

Fig. 3

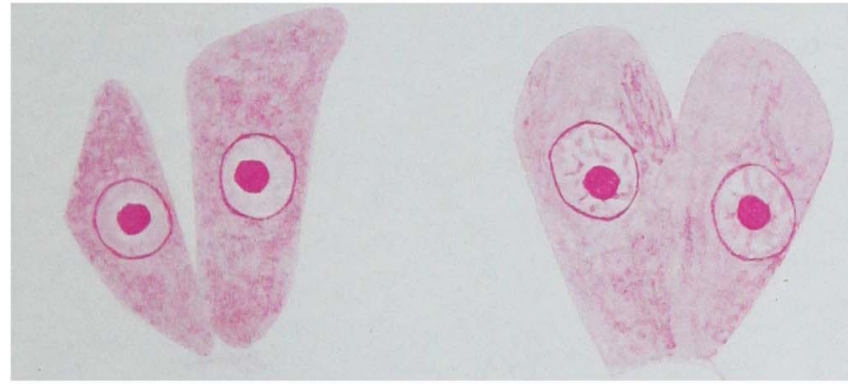

Fig. 4
Fig. 5

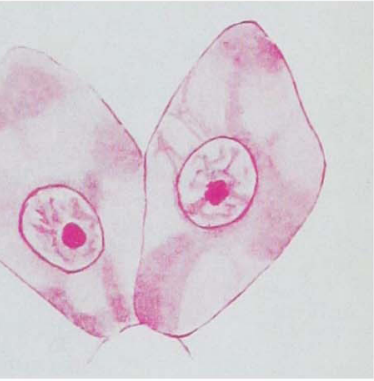

Fig. 6

S. Minamitani 